\title{
A comparative assessment of the antibacterial activity of root canal sealers on 2 Actinomyces species: An in vitro study
}

\author{
Małgorzata Pawińska ${ }^{1, A-F}$, Elżbieta Łuczaj-Cepowicz ${ }^{2, A-D}$, Grzegorz Szczurko, ${ }^{1, A-D}$, \\ Anna Kierklo ${ }^{3, A-C}$, Grażyna Marczuk-Kolada ${ }^{3, C-E}$, Katarzyna Leszczyńska ${ }^{4, B, C, F}$ \\ ${ }^{1}$ Department of Integrated Dentistry, Faculty of Medicine with the Division of Dentistry and Division of Medical Education in English, Medical University of Bialystok, Poland \\ ${ }^{2}$ Department of Pediatric Dentistry, Faculty of Medicine with the Division of Dentistry and Division of Medical Education in English, Medical University of Bialystok, Poland \\ ${ }^{3}$ Department of Dentistry Propedeutics, Faculty of Medicine with the Division of Dentistry and Division of Medical Education in English, Medical University of Bialystok, Poland \\ ${ }^{4}$ Department of Microbiology, Faculty of Medicine with the Division of Dentistry and Division of Medical Education in English, Medical University of Bialystok, Poland
}

A - research concept and design; B - collection and/or assembly of data; $\mathrm{C}$ - data analysis and interpretation;

$D$ - writing the article; $E$ - critical revision of the article; $F$ - final approval of the article

Address for correspondence

Grzegorz Szczurko

E-mail: grzesiekszczurko@gmail.com

Funding sources

This research was supported with a grant from the Medical University of Bialystok

(project No. 133-09752L).

Conflict of interest

None declared

Received on February 28, 2017

Reviewed on April 30, 2017

Accepted on September 26, 2017

Published online on August 7, 2018

Cite as

Pawińska M, Łuczaj-Cepowicz E, Szczurko G, Kierklo A, Marczuk-Kolada G, Leszczyńska K. A comparative assessment of the antibacterial activity of root canal sealers on 2 Actinomyces species: An in vitro study. Adv Clin Exp Med. 2019:28(2):243-248. doi:10.17219/acem/78022

DOI

10.17219/acem/78022

\section{Copyright}

Copyright by Author(s)

This is an article distributed under the terms of the

Creative Commons Attribution Non-Commercial License

(http://creativecommons.org/licenses/by-nc-nd/4.0/)

\section{Abstract}

Background. Actinomyces species have a low virulence and pathogenicity, but under specific circumstances they may be involved in root canal and periapical tissue infections.

Objectives. The aim of the study was to investigate the antibacterial activity of various root canal sealers on standardized strains of Actinomyces.

Material and methods. The materials tested in this study included AH Plus ${ }^{\mathrm{TM}}$ Jet (AH), Apexit ${ }^{\circledR}$ Plus (AP), Endomethasone N (EN), GuttaFlow ${ }^{\circledast}$ (GF), Hybrid Root SEAL (HB), MTA Fillapex (FL), Real ${ }^{\circledR}$ Seal (RCS), Roeko Seal Automix (RSA), Sealapex ${ }^{\mathrm{TM}}$ (SP), and Tubli-Seal ${ }^{\mathrm{TM}}$ (TS). The antibacterial effect of the freshly mixed sealers on standardized strains of Actinomyces israelii NCTC 8047 and Actinomyces viscosus ATCC 15987 was evaluated with the use of the agar diffusion test (ADT). The results were obtained with measuring the diameter of the growth inhibition zone at $96 \mathrm{~h}$ and 1,2,3, and 4 weeks, and were analyzed in time using repeated measures analysis of variance (ANOVA). Statistically significant differences among the materials were determined using one-way ANOVA and Tukey's post hoc testing. A paired Student's t-test was applied to compare the susceptibility of particular strains to each sealer. The critical level of significance for all tests was $p<0.05$.

Results. Most sealers demonstrated growth inhibition zones against both tested bacteria, except for RSA and GF. Actinomyces viscosus was significantly more susceptible than A. israelii to AP, RCS $(p<0.001)$ and TS ( $p=0.012$ ). Actinomyces israelii was significantly more susceptible than $A$. viscosus to EN, HB and SP $(p<0.001)$.

Conclusions. The antimicrobial effect of the examined materials varied considerably depending on the type of material and bacterial species tested. Most of the tested root canal sealers exhibited antibacterial activity on standardized strains of Actinomyces, with FL showing the highest antibacterial effect on both bacterial strains. Importantly, both standardized strains of Actinomyces were characterized by varied sensitivity to root canal sealers.

Key words: Actinomyces, antibacterial agents, root canal sealers 


\section{Introduction}

The genus Actinomyces contains Gram-positive, pleomorphic or filamentous, non-spore forming, non-motile, obligately and facultatively anaerobic bacteria. They are normal inhabitants of the oral microbiota and the primary colonizers of dental hard tissues. Although Actinomyces species have a low virulence and pathogenicity, under specific circumstances they may be involved in serious oral diseases, including root canal and periapical tissue infections. Most Actinomyces species have fimbriae - structures that enable bacterial cells to adhere to root canal walls and dentinal shavings forced out through the apical foramen during endodontic treatment. ${ }^{1}$ Moreover, fimbriae are involved in colonizing the extraradicular area by attaching to the cementum around the root apex and bacterial coaggregation. ${ }^{2}$ A recent study by Yamane et al. showed that Actinomyces species have a capacity to produce exopolysaccharides (EPSs), and thus contribute to biofilm formation, which can be essential to their pathogenic potential and the development of persistent infections in the periapical tissues. ${ }^{3}$

Bacterial cells embedded in an extracellular matrix can more easily survive in a nutritionally deprived environment and can evade neutrophilic phagocytosis and other host defense mechanisms. ${ }^{4}$ Actinomycotic colonies are known to have low pathogenicity, they also induce a minimal host response in the form of chronic endodontic infections, accompanied by the sinus tract, which discharges bright yellow granules referred to as sulfur granules. These granules consist of bacterial aggregates held together by an extracellular matrix. They are more likely formed in response to host defenses and can provide some resistance to phagocytosis or other immunological mechanisms. ${ }^{1}$ Several authors have reported that Actinomyces have been frequently cultured from the root canals of teeth with primary and post-treatment apical periodontitis. ${ }^{2,4-6}$ It is commonly believed that these bacteria are associated with persistent extraradicular infections, a lack of periradicular healing and cases of failed endodontic therapy. ${ }^{7-9}$ Actinomyces species are able either to survive intracanal procedures as resistant microorganisms or, as secondary invaders, to penetrate the root canal during or after endodontic therapy. ${ }^{2,10}$ In light of this evidence, the final stage of endodontic treatment - filling the root canal - becomes of significant importance. After chemomechanical preparation, the root canal should be obturated 3-dimensionally to entomb residual bacteria that could be untouched by irrigants or medications, and to prevent subsequent apical or coronal reinfection.

Most of the currently employed techniques used to obturate the root canal do not provide a long-term and fluid-tight seal within the entire root canal system. ${ }^{11,12}$ Therefore, the use of root-filling materials with antimicrobial properties may contribute to improving the outcome of endodontic treatment. ${ }^{13,14}$ This may be an interesting approach to intensify root canal disinfection.
Therefore, the aim of our study was to investigate and compare the antibacterial activity of various root canal sealers on standardized strains of Actinomyces.

\section{Material and methods}

Table 1 presents the materials used for the experiment and their composition.

\section{Strains and media}

The standardized Actinomyces israelii NCTC 8047 and Actinomyces viscosus ATCC 15987 strains were obtained from the Health Protection Agency (London, UK) and Microbiologics Inc. (St. Cloud, USA), respectively. The strains were cultured on Schaedler agar (Emapol sp. z o.o., Gdańsk, Poland), supplemented with $5 \%$ of sheep's blood for $48-72 \mathrm{~h}$ at $35-37^{\circ} \mathrm{C}$ under anaerobic conditions. The antibacterial activity of root canal sealers against the standardized strains of anaerobic bacteria was determined using the agar diffusion method on Brucella Blood Agar (Oxoid Limited, Basingstoke, UK), enriched with $5 \%$ of sheep's blood, vitamin $K_{1}$ and $1 \%$ of hemin. After $48-72 \mathrm{~h}$, suspensions of the bacterial strains in the Brucella broth of 1.0 on the McFarland turbidity scale were prepared.

\section{Agar diffusion test}

The bacterial suspension was distributed with a sterile cotton swab on the surface of Brucella Blood Agar with wells $7 \mathrm{~mm}$ in diameter and $5 \mathrm{~mm}$ in depth. In order to seal up the wells, the bottom was covered with $10 \mu \mathrm{L}$ of liquid Triptic Soya Agar (TSA) (Oxoid Limited), and the wells were filled with freshly mixed sealers prepared in aseptic conditions according to the manufacturer's instructions. The plates were left at room temperature for $30 \mathrm{~min}$, and then incubated for $96 \mathrm{~h}$ in anaerobic conditions at $37^{\circ} \mathrm{C}$. To control the growth of the standardized strain on the agar used for the experiment, positive control plates were streaked with bacteria, but no root canal sealers were used. Three samples were prepared for each material.

\section{Reading the size of the inhibition zone}

The plates were examined and evaluated for growth inhibition zones at $96 \mathrm{~h}$ and 1, 2, 3, and 4 weeks. An absence of bacterial growth around each well indicated antibacterial activity. The most uniform segment at the largest point of the growth inhibition zone was measured with a ruler, and the results were recorded in millimeters. A cut-off value of $7 \mathrm{~mm}$ (the diameter of the well) was subtracted from the measurement. ${ }^{15}$ Wider zones of inhibition were interpreted to indicate greater antimicrobial activity of the involved materials. 
Table 1. Compositions of materials tested for antibacterial activity

\begin{tabular}{|c|c|c|}
\hline Name & Source & Active ingredients \\
\hline AH Plus ${ }^{\mathrm{TM}}$ Jet & $\begin{array}{l}\text { Dentsply DeTrey GmbH, Konstanz, } \\
\text { Germany }\end{array}$ & $\begin{array}{c}\text { bisphenol-A epoxy resin, bisphenol-F epoxy resin, calcium tungstate, zirconium oxide, } \\
\text { silica, iron oxide pigments, dibenzyldiamine, aminoadamantane, tricyclodecane- } \\
\text { diamine, silicone oil }\end{array}$ \\
\hline Apexit ${ }^{\oplus}$ Plus & $\begin{array}{l}\text { Ivoclar Vivadent AG, Schaan, } \\
\text { Liechtenstein }\end{array}$ & $\begin{array}{c}\text { calcium salts (hydroxide, oxide, phosphate), hydrogenized colophony, disalicylate, } \\
\text { bismuth salts (oxide, carbonate), highly dispersed silicon dioxide, alkyl ester } \\
\text { of phosphoric acid }\end{array}$ \\
\hline $\begin{array}{l}\text { Endomethasone N } \\
\text { Eugenol }\end{array}$ & $\begin{array}{l}\text { Septodont Saint-Maur-des-Fossés, } \\
\text { Cedex, France } \\
\text { Chema-Elektromet, Rzeszów, Poland }\end{array}$ & $\begin{array}{c}\text { zinc oxide, hydrocortisone acetate, thymol iodide, barium sulfate, magnesium stearate } \\
\text { eugenol }\end{array}$ \\
\hline GuttaFlow ${ }^{\oplus}$ & $\begin{array}{l}\text { Coltene/Whaledent GmbH + Co. KG, } \\
\text { Langenau, Germany }\end{array}$ & $\begin{array}{l}\text { gutta-percha powder, polydimethylsiloxane, silicone oil, platinum catalyst, zirconium } \\
\text { dioxide, nanosilver, coloring }\end{array}$ \\
\hline Hybrid Root SEAL & $\begin{array}{l}\text { Sun Medical, Tokyo, Japan; } \\
\text { Parkell Inc., Farmingdale, USA }\end{array}$ & $\begin{array}{c}\text { liquid: 4-methacryloxyethyl trimellitate anhydride (4-META), 2-hydroxyethyl } \\
\text { methacrylate (HEMA), difunctional methacrylate monomers } \\
\text { powder: zirconium oxide, silica, hydrophilic initiator }\end{array}$ \\
\hline MTA Fillapex & $\begin{array}{l}\text { Angelus Ind. de Prod. Odontológicos } \\
\text { S/A, Londrina, Brazil }\end{array}$ & $\begin{array}{c}\text { paste A: salicylate resin, bismuth trioxide, fumed silica } \\
\text { paste B: fumed silica, titanium dioxide, mineral trioxide aggregate, base resin }\end{array}$ \\
\hline Real ${ }^{\oplus}$ Seal & SybronEndo Co., Orange, USA & $\begin{array}{l}\text { organic part: 1,6-bis(methacryloxy-2-ethoxycarbonylamino)-2,4,4-trimethylhexane } \\
\text { (UDMA), pyromellitic glycerol dimethacrylate (PEGDMA), ethoxylated bisphenol } \\
\text { A dimethacrylate (EBPADMA), ethylene glycol dimethacrylate (EDMA), bisphenol } \\
\text { A-glycidyl methacrylate (BisGMA) } \\
\text { inorganic part: barium borosilicate, barium sulfate, bismuth oxychloride, } \\
\text { calcium hydroxide, photoinitiators }\end{array}$ \\
\hline Roeko Seal Automix & $\begin{array}{l}\text { Coltene/Whaledent GmbH + Co. KG, } \\
\text { Langenau, Germany }\end{array}$ & polydimethylsiloxane, silicone oil, paraffin-base oil, platinum catalyst, zirconium dioxide \\
\hline Sealapex ${ }^{\mathrm{TM}}$ & Kerr Italia S.p.A., Salerno, Italy & $\begin{array}{c}\text { calcium oxide, bismuth trioxide, zinc oxide, sub-micron silica, } 2 \% \text { titanium dioxide, zinc } \\
\text { stearate, tricalcium phosphate, blend }\end{array}$ \\
\hline Tubli-Seal ${ }^{\mathrm{TM}}$ & Kerr Italia S.p.A., Salerno, Italy & zinc oxide, barium sulfate, oleo resin, oils/modifiers, thymol iodide, eugenol \\
\hline
\end{tabular}

\section{Statistical analysis}

The differences between the diameters of the bacterial growth inhibition zones over time were evaluated statistically by applying repeated measures analysis of variance (ANOVA). Statistically significant differences among the materials were determined by using one-way ANOVA and Tukey's post hoc testing. A paired Student's t-test was applied to compare the susceptibility of particular strains to each sealer. Statistical significance was set at $\mathrm{p}<0.05$. All statistical analyses were performed using SPSS v. 21.0 (IMB Corp., Armonk, USA).

\section{Results}

All data is presented in Tables 2-4 as means and standard deviations (SD) of the bacterial growth inhibition zones for each sealer. Zones of bacterial inhibition equal to 0 indicated that the sealer did not act during the whole experiment. Most sealers demonstrated growth inhibition zones against both tested bacteria, except for Roeko Seal Automix (RSA) and GuttaFlow ${ }^{\circledR}$ (GF). Positive control plates exhibited bacterial growth in all cases. Analysis of variance revealed that the size of the bacterial growth inhibition zone was significantly influenced by the kind of material tested $(\mathrm{p}<0.001)$.

The highest antibacterial effect against $A$. viscosus was exhibited by MTA Fillapex (FL), followed by Real ${ }^{\circledR}$ Seal (RCS),
Sealapex $^{\mathrm{TM}}(\mathrm{SP})$, Endomethasone N (EN), Apexit ${ }^{\circledR}$ Plus (AP), Tubli-Seal $^{\mathrm{TM}}$ (TS), Hybrid Root SEAL (HB), and AH Plus ${ }^{\text {TM }}$ Jet $(\mathrm{AH})$. The highest dimension of growth inhibition zones against $A$. israelii was revealed in FL, EN, SP HB, RCS, TS, $\mathrm{AH}$, and $\mathrm{AP}$, in a descending order. A comparison of the materials revealed significant differences between almost all the sealers in the varying sizes of growth inhibition zones within particular strains. Details of the statistical analysis results are presented in Table 2 .

To compare the susceptibility of particular strains to each sealer, the mean values of the growth inhibition zones obtained with all measurements for each material (excluding materials with a zone of growth inhibition of 0 ) were calculated and analyzed. Statistical analysis showed that $A$. viscosus was significantly more susceptible than A. israelii to AP, RCS ( $\mathrm{p}<0.001)$ and TS ( $\mathrm{p}=0.012)$. On the other hand, $A$. israelii was significantly more susceptible than $A$. viscosus to EN, HB and SP (p < 0.001) (Table 3 ).

The antibacterial effect of all the tested root canal sealers on individual strains varied considerably during the entire experiment. For $A$. israelii, the antibacterial activity of the materials (AH, EN, FL, and SP) increased significantly throughout the experiment $(\mathrm{AH}, \mathrm{FL}, \mathrm{SP} \mathrm{p}<0.001$; EN $p=0.037)$. The diameter of growth inhibition zones with AP and TS remained stable, and RCS showed a significant decrease in antibacterial action over time $(\mathrm{p}=0.045)$ (Table 4). For A. viscosus, the antibacterial effect of SP and RCS rose, whereas with FL and EN it decreased gradually. 


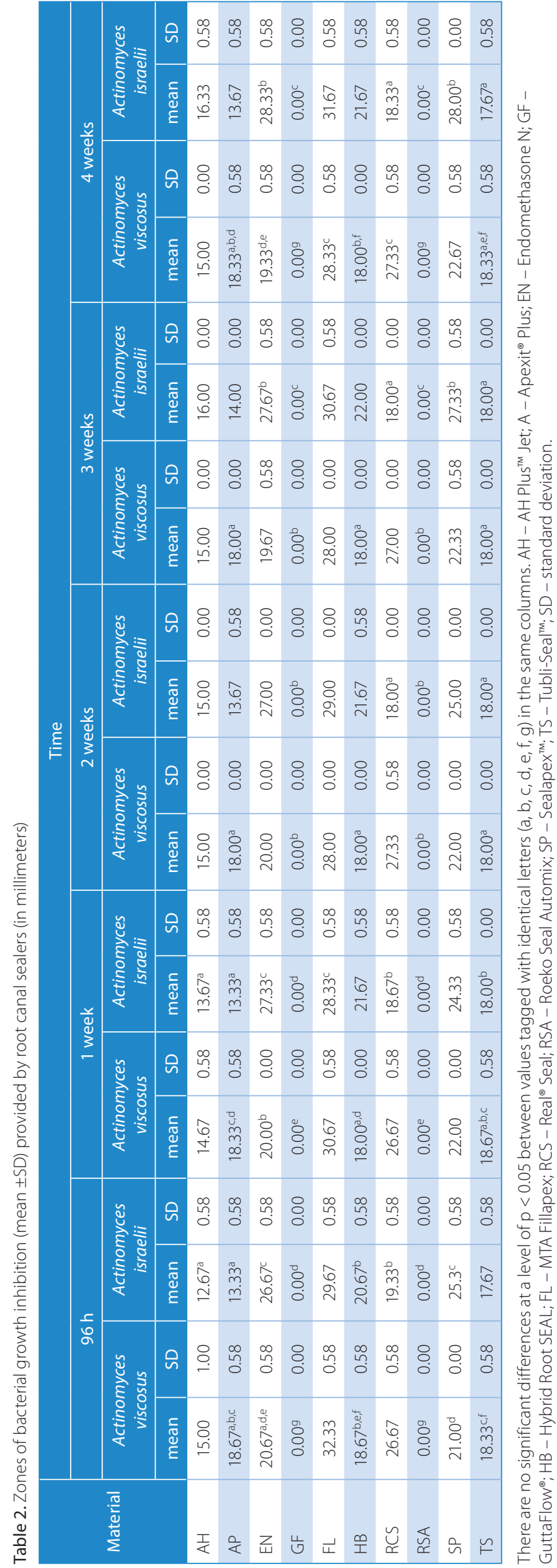

Table 3. Mean growth inhibition zones $[\mathrm{mm}]$ from all periods of observation for Actinomyces israelii and Actinomyces viscosus for each material (excluding materials showing no bacterial growth inhibition zone)

\begin{tabular}{|c|c|c|c|c|c|}
\hline Material & Strains & $\mathrm{N}$ & Mean & SD & p-value \\
\hline \multirow{2}{*}{$\mathrm{AH}$} & A. israelii & 15 & 14.73 & 1.49 & \multirow{2}{*}{ ns } \\
\hline & A. viscosus & 15 & 14.93 & 0.46 & \\
\hline \multirow{2}{*}{ AP } & A. israelii & 15 & 13.60 & 0.51 & \multirow{2}{*}{$<0.001$} \\
\hline & A. viscosus & 15 & 18.27 & 0.46 & \\
\hline \multirow{2}{*}{ EN } & A. israelii & 15 & 27.40 & 0.74 & \multirow{2}{*}{$<0.001$} \\
\hline & A. viscosus & 15 & 19.93 & 0.59 & \\
\hline \multirow{2}{*}{$\mathrm{FL}$} & A. israelii & 15 & 29.87 & 1.30 & \multirow{2}{*}{ ns } \\
\hline & A. viscosus & 15 & 29.47 & 1.92 & \\
\hline \multirow{2}{*}{$\mathrm{HB}$} & A. israelii & 15 & 21.53 & 0.64 & \multirow{2}{*}{$<0.001$} \\
\hline & A. viscosus & 15 & 18.13 & 0.35 & \\
\hline \multirow{2}{*}{ RCS } & A. israelii & 15 & 18.47 & 0.64 & \multirow{2}{*}{$<0.001$} \\
\hline & A. viscosus & 15 & 27.00 & 0.53 & \\
\hline \multirow{2}{*}{ SP } & A. israelii & 15 & 26.00 & 1.51 & \multirow{2}{*}{$<0.001$} \\
\hline & A. viscosus & 15 & 22.00 & 0.93 & \\
\hline \multirow{2}{*}{ TS } & A. israelii & 15 & 17.87 & 0.35 & \multirow{2}{*}{0.012} \\
\hline & A. viscosus & 15 & 18.27 & 0.46 & \\
\hline
\end{tabular}

ns - not significant. AH - AH Plus ${ }^{\mathrm{TM}}$ Jet; A - Apexit ${ }^{\oplus}$ Plus; EN - Endomethasone N; GF - GuttaFlow ${ }^{\bullet}$; HB - Hybrid Root SEAL; FL - MTA Fillapex; RCS - Real ${ }^{\oplus}$ Seal; RSA - Roeko Seal Automix; SP - Sealapex ${ }^{\text {TM; }}$;S - TubliSeal ${ }^{\mathrm{TM}} ;$ SD - standard deviation.

Table 4. Statistical analysis of the differences between the mean of bacterial growth inhibition zones over time exhibited by the sealers (excluding materials showing no bacterial growth inhibition zone)

\begin{tabular}{|l|c|c|}
\hline \multicolumn{1}{|c|}{ Material } & Actinomyces israelii & Actinomyces viscosus \\
\hline AH & $p<0.001^{*}$ & $p=0.925$ \\
\hline AP & $p=0.545$ & $p=0.461$ \\
\hline EN & $p=0.037^{*}$ & $p=0.045^{*}$ \\
\hline FL & $p<0.001^{*}$ & $p<0.001^{*}$ \\
\hline HB & $p=0.134$ & $p=0.045^{*}$ \\
\hline RCS & $p=0.045^{*}$ & $p=0.390$ \\
\hline SP & $p<0.001^{*}$ & $p=0.284$ \\
\hline TS & $p=0.633$ & $p=0.232$ \\
\hline
\end{tabular}

* level of significance $p<0.05$. AH - AH Plus ${ }^{T M}$ Jet; A - Apexit ${ }^{\oplus}$ Plus; EN - Endomethasone N; GF - GuttaFlow ${ }^{\oplus}$; HB - Hybrid Root SEAL; FL - MTA Fillapex; RCS - Real ${ }^{\oplus}$ Seal; RSA - Roeko Seal Automix; SP - Sealapex ${ }^{T M} ;$ TS - Tubli-Seal ${ }^{\mathrm{TM}}$.

The diameter of growth inhibition zones with AH, AP, $\mathrm{HB}$, and TS remained stable over the experimental period. Differences between the bacterial growth inhibition zones over time were not significant for almost all the tested materials $(p>0.05)$, with the exception of FL $(p<0.001)$ and EN ( $\mathrm{p}=0.045)$ (Table 4).

\section{Discussion}

The presence of bacteria in the root canal at the time of filling is the main causative factor of the initiation and perpetuation of apical periodontitis. Therefore, the eradication of bacteria from the root canal system should be the 
main goal of endodontic therapy. ${ }^{3,5,7}$ Although the cleaning and shaping of the root canals with various instrumentation techniques significantly reduces the intracanal bacterial load, complete eradication is still unattainable in many cases. Studies have demonstrated that after chemomechanical preparation, untouched biofilm remained in lateral canals, ramifications, isthmuses, and dentinal tubules. ${ }^{10}$ Persistent bacteria are able to induce or sustain apical periodontitis. ${ }^{5,9,10}$ Therefore, the use of root canal sealer with antimicrobial activity is widely recommended. ${ }^{2,14-18}$

Obturation of the root canal involves the use of guttapercha in combination with a sealer to provide an adequate seal. The use of a sealer is necessary to fill voids and gaps between the main material and root canal walls. Currently, numerous root canal sealers are available, based on various formulas, such as zinc oxide-eugenol paste, calcium hydroxide epoxy and methacrylate-based components, as well as mineral trioxide aggregate (MTA)- and silicone-containing materials. ${ }^{19}$ After being placed into the root canal system, sealers may penetrate into root canal irregularities. Supposing they have antimicrobial activity, sealers might help eliminate residual microorganisms unaffected by both chemomechanical preparation and intracanal medication. ${ }^{2,20,21}$

The agar diffusion test (ADT) is a well-established and simple method used to assess the antibacterial activity of dental materials. ${ }^{14,15,22,23}$ It is suitable for evaluating freshly mixed materials, allowing a direct comparison of sealers and indicating which sealers probably have antimicrobial action within the root canal system. However, the results of the ADT depend on the solubility of the material and its diffusibility in the culture medium used. ${ }^{23}$

It is extremely difficult to accurately compare bacterial inhibition data between different authors - even for identical materials - with the ADT due to difficulties in controlling the large number of variables. This means that there are no standardized in vitro protocols for testing the antimicrobial activity of materials. ${ }^{22}$

In this study, the vast majority of sealers showed an antimicrobial effect on both bacterial strains of Actinomyces. There were substantial differences in the antibacterial action of root canal sealers, which depended on the material tested and the bacterial strains used.

MTA Fillapex, EN, SP, and RCS produced the largest bacterial growth inhibition zones against both microorganisms at all times of the experiment. MTA Fillapex is a new material containing MTA - it simultaneously has the chemo-physical properties of a root canal sealer. Its antibacterial activity could be attributed precisely to MTA, which consists of calcium oxide and silicon dioxide, and produces calcium hydroxide on hydration, thus causing an increase in $\mathrm{pH} .{ }^{24}$ It has been shown that FL has $\mathrm{pH}$ values between 9.86 and 10.06. ${ }^{20}$ According to Estrela et al., at $\mathrm{pH}>9$, bacterial enzymes can be irreversibly inactivated, resulting in loss of their biological activity. $^{25}$
A similar mechanism of antibacterial action concerns calcium hydroxide root canal sealars (SP and AP), which in our study also inhibited the bacterial growth of both strains of Actinomyces. Faria-Junior et al. evaluated the antibiofilm activity on Enterococcus faecalis of various sealers in bovine dentine. ${ }^{20}$ Among the 7 materials studied, only FL and SP showed antibiofilm activity. The authors believe that this strong antibacterial effect of both sealers is not only related to the $\mathrm{pH}$ increase, but also to their high solubility. Morgental et al. claim that the antimicrobial potential of FL is comparable to zinc oxide-eugenol sealers, which have been used as a positive control in antimicrobial activity assays. ${ }^{23}$

Our results confirmed previous findings that both zinc oxide-eugenol containing sealers were effective in inhibiting the bacterial growth of Actinomyces. ${ }^{14,21}$ Eugenol, continuously eluted from these materials in relatively high concentrations, may contribute to their antibacterial activity by inhibiting cell growth or even inducing cell death. ${ }^{22,26}$

In the present study, $\mathrm{AH}$, an epoxy-based sealer, demonstrated less antimicrobial effect than zinc oxide-eugenol ones. Our findings are in agreement with other authors who studied identical materials against Actinomyces. ${ }^{14,21}$ Furthermore, Gjorgievska et al. noted that AH reduced bacterial growth much more when freshly mixed than after 21 days. ${ }^{14}$ The adverse effect of epoxy-resinbased sealers might be related either to bisphenol-A diglicidyl ether or the release of formaldehyde during the polymerization process. ${ }^{15}$ Both methacrylate-based sealers (RCS and HB) had a varied effect on the tested Actinomyces strains. Real ${ }^{\circledR}$ Seal inhibited A. viscosus much more strongly than $\mathrm{HB}$, whilst $\mathrm{HB}$, inhibited A. israelii much more than RCS. It has been hypothesized that the mechanism of antibacterial action of these materials may be explained by the toxicity of methacrylate resins and residual monomers leached from poorly polymerized materials. ${ }^{27}$ Some reports indicate that complete setting of methacrylate-based sealers can vary from $30 \mathrm{~min}$ to 7 days depending on the environment. ${ }^{28}$ Real ${ }^{\circledR}$ Seal SE and $\mathrm{HB}$ have been developed as alternatives to conventional endodontic sealers and gutta-percha. They offer the ability to bond to both root canal walls and the core material, and to create a so-called monoblock obturation to provide a durable hermetic seal, and therefore to ensure a favorable prognosis after endodontic therapy. However, there are also bad reviews. Nevertheless, a recently published in vivo study has not confirmed this assumption. ${ }^{29}$ Nawal et al. compared the antimicrobial efficacy of Epiphany ${ }^{\circledR}$ (identical to RCS) AH and GF on E. faecalis, using the ADT and the direct contact test (DCT). ${ }^{30}$ For both the ADT and DCT, Epiphany ${ }^{\circledR}$ produced a significant reduction in bacterial counts compared to the other 2 materials. Zhang et al. studied a new version of the sealer, Epiphany ${ }^{\circledR}$ SE (a self-adhesive sealer containing acidic monomers that are originally found in primers), with the DCT and reported that the freshly mixed material reduced the number 
of E. faecalis significantly within 60 min of contact with the bacterial suspension, but after setting it showed only slight antibacterial activity. ${ }^{18}$ On the other hand, other authors in their studies with the ADT and DCT demonstrated poor action of Epiphany ${ }^{\circledR}$ SE against E. faecalis, or they even observed an enhanced bacterial growth in contact with the material. ${ }^{13,20}$

In the present study, silicone-based root canal sealers (RSA and GF) were completely ineffective in inhibiting the bacterial growth of both Actinomyces strains. Our results are in accordance with findings of other authors who used the ADT. ${ }^{15,22,30}$ Cobankara et al. claimed that the absence of antibacterial activity might be caused by insolubility and a lack of diffusion of silicone materials in the agar medium. ${ }^{22}$

According to Gomes et al., in order to work effectively in terms of antimicrobial action, the materials used in endodontics should act both in the root canal space and at some distance into the dentinal tubules, and even reach the outer root surface. ${ }^{31}$

\section{Conclusions}

We have shown that the antimicrobial effect of the examined materials varied considerably depending on the type of material and bacterial species tested. We have established that most of the tested root canal sealers exhibited antibacterial activity on standardized strains of Actinomyces, with FL showing the highest antibacterial effect on both bacterial strains. Importantly, both standardized strains of Actinomyces were characterized by varied sensitivity to the root canal sealers.

\section{References}

1. Siqueira JF Jr. Periapical actinomycosis and infection with Propionibacterium propionicus. Endod Topics. 2003;6:78-95.

2. Wang J, Jiang Y, Chen W, Zhu C, Liang J. Bacterial flora and extraradicular biofilm associated with the apical segment of teeth with posttreatment apical periodontitis. J Endod. 2012;38(7):954-959.

3. Yamane K, Yamanaka TN, Ishihara K, et al. Pathogenicity of exopolysaccharide-producing Actinomycesoris isolated from an apical abscess lesion. Int Endod J. 2013;46(2):145-154.

4. Nair PNR, Brundin M, Sundqvist G, Sjögren U. Building biofilms in vital host tissues: A survival strategy of Actinomyces radicidentis. Oral Surg Oral Med Oral Pathol Oral Radiol Endod. 2008;106(4):595-603.

5. Subramanian K, Mickel AK. Molecular analysis of persistent periradicular lesions and root ends reveals a diverse microbial profile. J Endod. 2009;35(7):950-957.

6. Al-Ahmadi A, Ameen $\mathrm{H}$, Pelz K, et al. Antibiotic resistance and capacity for biofilm formation of different bacteria isolated from endodontic infections associated with root-filled teeth. J Endod. 2014;40(2): 223-230.

7. Tennert C, Fuhrmann N, Wittmer A, et al. New bacterial composition in primary and persistent/secondary endodontic infections with respect to clinical and radiographic findings. J Endod. 2014;40(2): 670-677.

8. Signoretti FG, Endo MS, Brenda PF, et al. Persistent extraradicular infection in root-filled asymptomatic human tooth: Scanning electron microscopic analysis and microbial investigation after apical microsurgery. J Endod. 2011;37(12):1696-1700.
9. Signoretti FG, Gomes PF, Montagner F, Jacinto RC. Investigation of cultivable bacteria isolated from longstanding retreatment-resistant lesions of teeth with apical periodontitis. J Endod. 2013;39(10):12401244.

10. Rocas IN, Lima KC, Siqueira JF Jr. Reduction in bacterial counts in infected root canals after rotary or hand nickel-titanium instrumentation: A clinical study. Int Endod J. 2013;46(7):681-687.

11. Hammad M, Qualtrough A, Silikas N. Evaluation of root canal obturation: A three-dimensional in vitro study. J Endod. 2009;35(4): 541-544.

12. Li G, Niu L, Zhang W, et al. Ability of new obturation materials to improve the seal of the root canal system: A review. Acta Biomater. 2014;10(3):1050-1063.

13. Slutzky-Goldberg I, Slutzky H, Solomonov M, Moshonov J, Weiss El, Matalon S. Antibacterial properties of four endodontic sealers. J Endod. 2008;34(6):735-738.

14. Gjorgievska E, Apostolska S, Dimkov A, Nicholson JW, Kaftandzieva $A$. Incorporation of antimicrobial agents can be used to enhance the antibacterial effect of endodontic sealers. Dent Mater. 2013;29(3): 29-34.

15. Eldeniz AU, Erdemir A, Hadimli HH, Belli S, Erganis O. Assessment of antibacterial activity of EndoREZ. Oral Surg Oral Med Oral Pathol Oral Radiol Endod. 2006;102(1):119-126.

16. Bailon-Sanchez ME, Baca P, Ruiz-Linares M, Ferrer-Luque CM. Antibacterial and anti-biofilm activity of AH Plus with chlorhexidine and cetrimide. J Endod. 2014;40(2):977-981.

17. Barros J, Silva MG, Rocas IN, et al. Antibiofilm effects of endodontic sealers containing quaternary ammonium polyethylenimine nanoparticles. J Endod. 2014;40(2):1167-1171.

18. Zhang $H$, Shen $Y$, Ruse ND, Haapasalo M. Antibacterial activity of endodontic sealers by modified direct contact test against Enteroccocus faecalis. J Endod. 2009;35(4):1051-1055.

19. Reszka P, Nowicka A, Lipski M, Dura W, Droździk A, Woźniak K. A comparative chemical study of calcium silicate-containing and epoxy resin-based root canal sealers. Biomed Res Int. 2016; 2016:9808432. doi: 10.1155/2016/9808432

20. Faria-Junior NB, Tanomaru-Filho M, Berbert FL, Guerreiro-Tanomaru JM. Antibiofilm activity, $\mathrm{pH}$ and solubility of endodontic sealers. Int Endod J. 2013;46(8):755-762.

21. Barbero-Navarro I, Galera-Ruiz H, Pereira M, Guerreiro D, Machuca-Portillo MC, López del Valle L. In vitro antimicrobial effects of 3 root canal sealers on Actinomyces radicidentis. P R Health Sci J. 2014;33(2):71-73.

22. Cobankara FK, Altinoz HC, Erganis O, Kav K, Belli S. In vitro antibacterial activities of root canal sealers by using two different methods. J Endod. 2004;30(1):57-60.

23. Morgental RD, Vier-Pelisser FV, Oliveira SD, Antunes FC, Cogo DM, Kopper PM. Antibacterial activity of two MTA-based root canal sealers. Int Endod J. 2011;44(12):1128-1133.

24. Mohammadi Z, Shalavi S, Giardino L, Palazzi F, Mashouf RY, Soltanian A. Antimicrobial effect of three new and two established root canal irrigation solutions. Gen Dent. 2012;60(6):534-537.

25. Estrela C, Sydney GB, Bammann LL, Felippe O Jr. Mechanism of action of calcium and hydroxyl ions of calcium hydroxide on tissue and bacteria. Braz Dent J. 1995;6(2):85-90.

26. Sipert CR, Hussne RP, Nishiyama CK, Torres SA. In vitro antimicrobial activity of Fill Canal, Sealapex, Mineral Trioxide Aggregate, Portland cement and EndoRez. Int Endod J. 2005;38(8):539-543.

27. Bouillaguet S, Wataha JC, Tay FR, Brackett MG, Lockwood PE. Initial in vitro biological response to contemporary endodontic sealers. J Endod. 2006;32(10):989-992.

28. Nielsen BA, Beeler WJ, Vy C, Baumgartner JC. Setting times of resilon and other sealers in aerobic and anaerobic environments. J Endod. 2006;32(10):130-132.

29. Barborka BJ, Woodmansey KF, Glickman GN, Schneiderman E, He J. Long-term clinical outcome of teeth obturated with Resilon. J Endod. 2017;43(4):556-560.

30. Nawal RR, Parande M, Sehgal R, Naik A, Rao NR. A comparative evaluation of antimicrobial efficacy and flow properties for Epiphany, Guttaflow and AH-Plus sealer. Int Endod J. 2011;44(4):307-313.

31. Gomes PF, Montagner F, Bellocchio Berber V, et al. Antimicrobial action of intracanal medicaments on the external root surface. J Dent. 2009;37(1):76-81. 